\title{
Nova era para a acreditação de laboratórios
}

A Sociedade Brasileira de Patologia Clínica/Medicina Laboratorial (SBPC/ML) vem sendo pioneira no movimento pela qualidade na saúde no Brasil, e por isso tornou-se um posto privilegiado para acompanharmos estas tendências.

Há décadas a SBPC/ML criou e mantém, em parceria com a empresa Control-Lab, o Programa de Proficiência em Ensaios Laboratoriais (PELM), que conta com pleno reconhecimento da comunidade laboratorial e, recentemente, também da Agência Nacional de Vigilância Sanitária (ANVISA), por meio da certificação da Rede Brasileira de Laboratórios Analíticos em Saúde (REBLAS). Este programa, desde o seu início voluntário, traz aos seus participantes subsídios preciosos para a melhoria contínua, encontrando-se também, ele mesmo, em constantes evolução e reformulação. Pois bem, agora podemos acompanhar, como tendência colocada na Consulta Pública n. 50 de 2005 (ANVISA), a qual pode se concretizar em forma de Resolução da Diretoria Colegiada - uma RDC de caráter obrigatório -, 0 reconhecimento pela autoridade sanitária de que a participação em programas de proficiência é fundamental para garantir a segurança da população atendida pelos laboratórios brasileiros. A SBPC/ML se alinha com a ANVISA e fará todos os esforços para que os laboratórios clínicos possam se adequar a essa exigência.

Ainda há menos de uma década, a SBPC/ML criou e mantém o Programa de Acreditação de Laboratórios Clíni$\cos (P A L C)$, também pioneiro, que permite aos laboratórios participantes acesso às melhores práticas em medicina laboratorial. Esse acesso se inicia no momento do estudo e da implantação dos requisitos, mas se aprofunda com as auditorias realizadas por pares, as quais se constituem em momentos de rica troca técnica e pessoal para auditores e auditados. Os laboratórios participantes podem melhor testemunhar o que significa participar desse seleto grupo de vanguarda, e o fazem sempre.

Contudo acreditamos que os princípios das boas práticas e os conhecimentos que hoje a SBPC/ML detém devam ser democratizados e colocados ao alcance de todos os laboratórios e, mais importante, dos pacientes por eles atendidos. Em função disso, a SBPC/ML permanecerá mantendo e ampliando o PALC, e continuará colaborando com iniciativas governamentais, como a Organização Nacional de Acreditação (ONA) e a ANVISA por meio de cooperação técnica. Ao mesmo tempo, está em finalização um ambicioso projeto para a divulgação do PALC aos médicos. Eles terão papel fundamental em valorizar e prestigiar os laboratórios acreditados.

Hoje a palavra acreditação entrou definitivamente para a agenda nacional, e temos todas as evidências, partindo inclusive de compradores de serviços, de que o reconhecimento de um prestador se fará na medida de sua qualificação. E cremos que isso não se dará apenas no âmbito dos laboratórios, mas de todas as instituições de saúde. Os leitores do JBP estão conclamados a se aproximarem dos programas de proficiência e de acreditação, se ainda não o fizeram, para que possam também fazer parte desse movimento inexorável pela melhoria da qualidade e da efetividade da medicina no país. 